\title{
Legal Analysis of Children's Right to Play
}

\author{
Mei Liu \\ Kunming University \\ Kunming, China
}

\begin{abstract}
The right to play is one of the basic rights that children should have and the legal protection and practice the right to play are closely related to the healthy growth of children. Considering the great importance of the right to play for the development of children, this article starts with the value of children's right to play and discusses the legal basis and protection of children's right to play.
\end{abstract}

Keywords—children; play; right to play

\section{INTRODUCTION}

Article 31 of the Convention on the Rights of the Child provides: "State parties recognize the right of child to rest and leisure, to engage in play and recreational activities appropriate to the age of the child and to participate freely in cultural and arts." This provision is the direct results that modern people have been paying more and attentions to the rights of children to play, especially the international communities have been working hard and appealing to promote the protection of the rights for a long time. The confirmation that modern society has made on the rights of children to play from human rights and spirits is a breakthrough initiation for the human civilization. It has completely overturned the theory that the people are imprisoned in by traditional culture holding the views that games are evils and of no benefit, which indicate or symbolize that human being has taken a firm step on the way in pursuit of liberation.

As a basic right, the child's right to play was finally established after the release of the 1989 Convention on the Rights of the Child, as the state party, China started seriously to treat the play and provided "Kindergartens should take the play as a basic activity" in the Teaching Guideline for Preschool Education (Trial) in 2001. Though the policies concerned have promoted the development of the protection of children's rights and interests in China, yet children's rights to play are not clearly stated. Currently the preschool children's rights to play are severely violated. First, the opportunities for children to play are unfeeling deprived, mainly because of heavy learning tasks and lack of time to play. Second, the children's to play are distorted. Teaching plays occupy the time of children's right to play freely. Third, the low quality toys on the market do harm to children's health. Fourth, the social resources and facilities for children to play are imperfect.

In fact, among the children's rights which have been recognized and confirmed widely around the world, the right to play is far less than the right to life and the right to development and the right to education, which are more arresting, and it is often concealed or replaced by other interests. Currently the legislation at home concerning the protection of children's right to play can be only found through terms such as culture and entertainment, physical exercises, rest, extracurricular activities and so on, and there are still no clear provision that indicates the children's right to play. This situation makes us impossible to protect children's right to play by laws.

\section{LEGAL BASIS FOR CHILDREN'S RIGHT TO PLAY}

\section{A. The Rightt to Play Is One of the Basic Human Rights for Children as Common Citizens}

In the children's rights system, the weight of various rights is unequal. Some rights are fundamental such as the right to life. Some are indemnificatory, the enrichment and perfection of such rights are important guarantees for individuals to realize the value of life, otherwise, even if the individuals are alive, it will be difficult for them to expand, fill and enrich. Such rights mainly include the right to education, the right to entertainment, the right to rest, the right to leisure, the right to participation, the right to know, the right to personal dignity, the right to play and so on.

Though the right to play can not be taken as a basic right of children, yet seen from security, the right to play is also an indispensable part to improve children's lives and life. Through observations, we can find that every child may play and look for chances to play wherever they are. Studies show that beyond all doubt, the deprivation of plays and violation against children's rights to pay will do ham to the perfection of the children's lives and life. Therefore, even if there are differences between basic rights and the protective rights, yet the right to play is not an extra luxury after the consideration of other rights. Children's plays and entertainment, learning and rest make the children's life rich and diverse in practice, which form a unique life world and practice for children. They are parts of children's activities and also the freedom and rights to be protected for children. Children's rights to play, entertainment, learning and rest are sourced from the children's freedom and the right to life, and the children's right to play shall get the same or more attentions the same as the right to life, the right to development, and the right to education. Because the importance of children's right to play is not only reflected in recognition of the people on the value of the plays, but also further shows that the people give more attentions and understanding to the player-children's development. The analysis of children's rights to play show 
that the children's rights to play has no actual legal effect in China, and the rights and positions are not carried out as well in practice; among the whole system of rights, children's rights to play is integrated to the protective rights, which is regarded "a supplement right and a right that matters nothing" by most.

No doubt, the views can not deny the moral basis to make the play be one of the children's rights, on the contrary, it shows that in order to promote the realization of children's rights to play, governments, the society and the public need to make more efforts.

\section{B. The Right to Play Is A Special Right to Children as Special Citizens}

Children have not only an identity of ordinary citizens but also an identity of special citizens, this "special" is reflected on two roles, namely students and children. Yet in most occasions, teachers and parents are just regarding children as students but ignoring some of their basic needs as children, such as the nature of playing as children. One of the most important reasons for the situation is that the right to education is overstressed in the modern society, which becomes a core right of the children over others. However with more and more attentions paid to education, children's right to play is gradually exiled, which causes the role of children to be covered by the rule of students. Today, the exam-oriented education still exists, the students are separated from the innocence, and instead, scores become a measure to weigh the quality of children. Under the situation, the role of student is separated from the role of child on the same child, and the role of children together with plays are exiled to the preschool world, the play has been taken as a bad factor against the students' development. Teachers and parents do all what they can to push the play out of the learning, and the education is increasingly becoming a "tyranny", and the students are controlled by the on-time classes and curriculum plans, which can be seen obviously in primary and middle schools. The intense learning rhythm lasts till after class and the adults' commands make been heavy burdens for the children to bear all day long, and the unfettered plays have to be seen only in dreams. So we need to reconsider the value and significance of the play for children and ultimately return the plays to the children's life through a pure and simple form. Based on this point, we take the right to play as a right for roles to appeal. In recent decades, children's survival and development have attracted more and more attentions of far-sighted persons. Chinese Children Development Program (2001-2010) also clearly provides: provide children necessary times for leisure and entertainment, protect the children's rights of participation in family, social and cultural life; increase after-school activity facilities and places for children education, science and technology, culture, sports, entertainment and so on, $90 \%$ or more of counties (cities) shall have one after-school activity place at least for children. Compared to the constitution, the policies and regulations provide more direct legal support for students rights to play. Though there is still a certain distance between the text and the reality, yet it has taken a further step to understand the children's rights to play.

\section{DETAILS OF CHILDREN'S RIGHT TO PLAY}

\section{A. Free To Play}

What the play is has been discussed for a long time, and it is also defined in diversity, yet there is a point shared by all that the play is free but not mandatory, which determines that the core of children's right to play shall be free to play. But such freedom shall not be out of control, and anyone is not allowed to get the freedom of his own through depriving that of others. Eriksson ever said: "Where freedom is stopped or limited, the play will end there."

1) Independence of play: Children are players of the play, that is, and under certain conditions, the children shall have rights and abilities of control over the activities of their own. The core of the independence of play is the right to select the play independently. We should not designate what the children should play, that is, the children may play what they want, decide how to play, whom to play with and how long to play. The plays that teachers try their best to design are just "what our teachers require use to play" in the eyes of the children." Of course, we should not let the children go out of control and limit, and the restrictions on the independence shall be stated in the rights of adult intervention. In addition, we should provide children necessary possibilities to exercise the independence, if the children are provided with single activity materials for play, the so called independence will end like a bubble. Studies show that if the play materials provided to children are not selectable, there will be a higher proportion of children who do nothing. If children may select the materials for play, there will be lower proportion of children doing nothing, and the frequency for children to communicate will be higher. Seen from the point, we can draw a conclusion that the availability of materials for play will directly affect the enthusiasm of children to participate. So it is necessary to provide children sufficient materials for the children to play, which will be fully independent. No doubt we do not mean that the more the materials are the better the plays are, too many selections may lead children to fail in a play, which will affect the play effect.

2) Right to participate: For children's physical and mental states are not fully mature, when facing problems relative to the interests of their own, they often feel difficult to make effective decisions, yet this shall not be a reason to deny the right of children to self decision, it is a must for us to acknowledge children are main bodies of positive rights, who are individuals with dignity and independent values, and they may freely show their attitudes before affairs related to them, showing what they feel and expressing what they what However, we must member that children are an irrational group, who may commit behaviors that may harm themselves or others in the play, or violate rules of the play leading to failure of the play, such a situation will need the intervention of adults so as to better ensure the realization of children's independence. Therefore, adults shall be kept cautious when dealing with the independence of play and the right to intervention, it needs to well grasp the time of intervention and exit so as to maximize the children's freedom of play. 


\section{B. Safeguard of Children's Right to Play}

The right of the game is a higher level of the right to request. In our country, around the political, cultural, economic development is not balanced, which resulted in the children around the family, where the kindergarten and community game conditions are obvious. Only talk about the right to freedom of the game can not achieve real game rights equality. Game protection rights include the following three parts.

1) To enjoy play facilities equally: Children are equal to use play facilities at home, kindergartens and communities, which is divided into two parts: first, the right to equal opportunities for the play; second, the right to equally use the play conditions. The right for equal opportunities to play includes equal and appropriate chances to play. First, adults should ensure that all children can participate in the play activities, second, adults should provide children with right play chances and ensure what the children play are what they want. If the play activities provided to children are inadequate, it will cause the failure of some children to find what they want. Besides, if there are equal chances for children to select, the children followed will be unable to choose what they like. The right to equally use the play conditions is that children are equal to use all educational and educational facilities in schools, which usually include playing site and facilities.

2) To create necessary play facilities: If the play facilities existing are not complete, the children shall have the right to request the government to provide play facilities in line with national standards. Take the pre-school education as an example, for the pre-school education is non-obligatory in the country, to which the government fails to value, as a result, the costs used for the pre-school education development occupies $1.2-1.3 \%$ of the national education funds. Therefore, the country is appealed to increase investment to improve children's play facilities. In cases the play facilities are not complete or missing, the children shall have the right to request the country to create play facilities.

3) To keep the play facilities in safety: With full play facilities provided, the country still has to keep the play facilities safe, and the children shall have the right to request the state to provide play facilities which shall be healthy and meeting sanitary standards, which can be seen in many laws and regulations. Article 44 in Education Law of the PRC provide: Administrative departments of education, sports and public health, and schools or other institutions of education shall improve sports and health care facilities to ensure students good health both in body and in mind. Article 19 in the Kindergarten Management Rule provides: Kindergarten shall establish safety and protective systems, forbidding dangerous buildings and facilities which do harm to the children's safety, say no to use poisonous and harmful substances to make teaching tools and toys. Besides, it describes the duty scope of supervision and management of educational administrative departments and legal responsibilities for law violation. Article 27 of it provides, if the houses or facilities in a kindergarten fail to meet national healthy standard, safety standard or do harm to children's health or threaten the life safety, the kindergarten shall be suspended and asked to modify it within a given time. Article 27 of it provides, if any poisonous or harmful substances are used to make teaching tools or toys, the persons responsible shall be directly warned or fined by the educational administrative departments. If it is extremely severe, judiciary authorities will investigate for criminal responsibilities. Seen from these, the laws and rules concerning the safety protection of play facilities in kindergartens are relatively complete.

\section{CONCLUSION}

The protection and respect to children's the rights to play need national laws, power of governments and schools, as well as the cooperation and supports of thousands and thousands of families, and every adult is expected to honor children's desires to play so as to meet what they want.

\section{REFERENCES}

[1] Ding Haidong, Value of Children's Right to Play and Actual Dilemma in China [J]. Journal of Northeast Normal University(Philosophy and Social Sciences, 2010,(5).

[2] Cited from Huang Jin, Play Spirit and Kindergarten Education [M] Nanjing: Jiangsu Education Publishing House, 2005. 